TEACHING TACTIC

\title{
“Town Hall Meeting” on the Bible in Contemporary Issues
}

\author{
Chan Sok Park \\ The College of Wooster
}

\section{The context}

This exercise is designed for an undergraduate upper-level, seminar-based course (with approximately twenty students) on the use and misuse of the Bible in contemporary contentious issues in a small liberal arts college context.

\section{The pedagogical purpose}

Students cultivate more informed and sympathetic views of the use of different biblical interpretations in contested contemporary issues, becoming active "co-constructors" of class learning by sharing their research with their peers.

\section{Description of the strategy}

Early in the semester, I introduce the idea of the "town hall meeting." I divide the class into groups of three to four students to select, research, and write a report on a controversial contemporary issue for which a range of interpretations of biblical texts have played authoritative roles in both academic and popular debates. Possible topics include: religious violence, economic justice, gender and human sexuality, ecology and environmentalism, immigration and refugee, race and racism, and slavery and modern human trafficking. The goal of the written report (approximately ten pages, properly cited), which will be shared with the entire class prior to the debate, is to identify the main issues at stake and a spectrum of different positions on the topic, and to examine how pertinent biblical texts have informed the debate over the issue in one way or another.

In the second half of the semester, each group takes a fifty-minute class session to host their town hall meeting. Each group member gives an opening statement to succinctly introduce a pre-assigned position on the issue. (Note that each member must stay "in character" throughout the debate regardless of their own positions on the topic.) Then the floor is opened to questions and comments from the rest of the class (who have read the group's report in advance). After the debate, we debrief: panelists reflect upon what they learned from arguing for particular positions on the topic, especially when different from their own; the rest of the class provides constructive feedback to the group. Both the written report and the town hall debate are graded on (1) subject knowledge; (2) structure and creativity in presentation; and (3) teamwork and individual contribution. Grades are typically assigned to the entire group with the exception of individual member's absences or poor participation.

\section{Why it is effective}

This activity enhances students' interest in, and comprehension of, their chosen topic through active learning and inductive pedagogy. Rather than passively listening to lectures on hermeneutical principles and the use of the Bible in ethical discourses and case studies, students take the initiative to research a specific problem or issue of interest to them, and discover for themselves the need for additional resources to better understand what is at stake in a given case. In order to be attentive to potential challenges of inductive pedagogy I periodically monitor each group's progress in the preparatory phase. 